\title{
AGIR COMUNICATIVO E DEMOCRACIA: UMA PROPOSTA PARA A LEGITIMAÇÃO DA JURISDIÇÃO CONSTITUCIONAL
}

\author{
COMMUNICATIVE ACTION AND DEMOCRACY: A PROPOSAL \\ FOR THE LEGITIMATION OF CONSTITUTIONAL \\ JURISDICTION \\ Willy Potrich da Silva ${ }^{1}$ \\ Américo Bedê Freire Jr. ${ }^{1}$
}

Recebido em: 28/11/2017 Aceito em: 07/06/2018

willypotrich@hotmail.com bede@jfes.jus.br
Resumo: Enxergando o direito como o médium da integração social que outrora era relegada à religião ou a outros fundamentos transcendentais, Habermas buscará aplicar sua teoria do agir comunicativo ao momento de criação do direito positivo, inserindo no processo legislativo aspectos de uma moral e de uma democracia procedimentais, materializadas por seu princípio do discurso, tendo como pano de fundo os direitos fundamentais e a soberania popular. Conjugado o pensamento habermasiano com a sensível mudança na prática da jurisdição - especialmente a constitucional - a partir da aceitação dos princípios como espécie normativa, e em especial após a mudança do paradigma liberal para o paradigma do bem estar social (diagnóstico que é compartilhado por Habermas), propõe-se a reflexão acerca da possibilidade de transposição de sua teoria do agir comunicativo como resposta aos questionamentos frequentes a respeito da legitimidade democrática das cortes constitucionais na tomada de decisões que parecem complementar a atividade do legislador democrático.

Palavras-chave: Jurisdição constitucional. Teoria do agir comunicativo. Democracia. Legitimação.

\begin{abstract}
Viewed from the perspective of the medium of social integration that was once relegated to religion or other transcendental foundations, Habermas will seek to apply his theory of communicative action to the creation of positive law by inserting in the legislative process aspects of a moral and procedural democracy, materialized by its principle of discourse, having as background the fundamental rights and the popular sovereignty. Conjugated the Habermasian thought with the sensible change in the practice of the jurisdiction - especially the constitutional one - from the acceptance of the principles like normative species, and in particular after the change of the liberal paradigm to the wellfare state paradigma (diagnosis that is shared by Habermas), it is proposed to reflect on the possibility of transposing his theory of communicative action as a response to frequent questions about the democratic legitimacy of constitutional courts in decision-making that seem to complement the activity of the democratic legislator.
\end{abstract}

Keywords: Constitutional Jurisdiction. Theory of communicative action. Democracy. Legitimacy.

\section{INTRODUÇÃO}

Dado o caráter extremamente aberto de parcela significativa dos enunciados normativos, sobretudo daqueles que formam o texto da Constituição Federal de 1988, não é de se estranhar uma sensação cada vez mais evidente de aproximação entre as atividades de elaboração e aplicação das normas, sobretudo no âmbito da jurisdição constitucional.

\footnotetext{
${ }^{1}$ Faculdade de Direito de Vitória - FDV - Vitória - Espírito Santo - Brasil
} 
A concepção, desde Dworkin, de um ordenamento jurídico composto por regras e princípios, entendido como íntegro e capaz de fornecer todas as respostas, mesmo diante de casos aparentemente não regulados, força o intérprete do Direito a buscar instrumentos capazes de fazerem frente ao tamanho da tarefa, sem escapar dos limites impostos pelo próprio código do direito.

As técnicas sofisticadas - ou não - de argumentação postas à disposição do intérprete para fins de modelar os textos normativos diante dos casos concretos, abandonam progressivamente a ideia mecanicista de subsunção e valorizam a construção argumentativa do direito, no que aproximam, cada vez mais, os argumentos jurídicos dos argumentos atinentes à moral, e afastam a jurisdição das amarras inerentes a uma singela aplicação.

Paralelamente, o fim do paradigma do Estado Liberal e o surgimento do paradigma do Estado de Bem Estar Social acentuam o caráter instrumental do médium do direito, que passa a ser utilizado de forma maciça como meio à disposição do poder estatal para alcançar a tão desejada harmonia entre o capital e o socialismo².

Nesse contexto, os programas políticos implementados no contexto do Estado Social, por meio do direito, deixam sempre transparecer de forma mais ou menos claras os fins pretendidos. Negligenciam, porém, em grande medida, os meios que se colocam à disposição do Estado no exercício de sua função administrativa para fazer valer novas posições jurídicas de vantagem que surgem em prol da coletividade, materializadas em direitos sociais. Como consectário, conferem também à jurisdição papel ativo na implementação ativa desses programas, sob a cobertura de limites muito parcamente definidos.

Assim, a tessitura aberta dos princípios, que se travestem na forma dos direitos fundamentais, reclama do Estado juiz a criação da norma menos abstrata capaz de regular, com clareza mínima, casos concretos, lastreadas em limites pouco evidentes ou mesmo contraditórios previamente estabelecidos pelo Estado legislador.

O quadro que ora se destaca parece ganhar ainda mais relevo quando se toca no sistema de precedentes que, paulatinamente, vem se construindo e se firmando no Brasil, especialmente à partir da edição do Código de Processo Civil de 2015 (Lei 13.105/2015), sem que se possa deixar de mencionar as súmulas vinculantes no âmbito do Supremo Tribunal Federal (art. 103-A da CRFB/88, acrescido pela EC/45) e a atuação do mesmo Tribunal no controle abstrato de constitucionalidade.

Em todos esses níveis, a jurisdição, outrora pensada como função quase mecanicista de interpretação e aplicação do direito positivo, assume uma dimensão verdadeiramente criativa, trazendo para si questionamentos acerca da legitimidade democrática que pressupõe a função de legislar.

Essa função criativa coloca o juiz - e aqui, mais notadamente, aqueles que atuam no âmbito da jurisdição constitucional - em um papel misto, num meio termo entre as funções clássicas de legislador (sem qualquer conotação crítica) e de julgador.

Por isso, essa função criativa inerente ao exercício da jurisdição atrai para as decisões, especialmente do Tribunal Constitucional, e sobretudo naqueles casos em que sua eficácia

\footnotetext{
${ }^{2}$ Direito e Democracia: entre facticidade e validade, vol. 2. Tempo Brasileiro: 2000. p. 195.
} 
ultrapassa o círculo jurídico de partes litigantes, o mesmo ônus, quanto à sua legitimação, que se extrai do próprio direito, pensado em termos de sua produção legislativa.

Não basta, por isso, invocar o direito positivo como fator suficiente de legitimação de toda e qualquer decisão tomada pelo Estado no exercício da função jurisdicional, já que esta função não se autolimita à interpretação e aplicação pura e simples de um direito já legitimado criado pelo legislador eleito, mas vai além, e cria ela própria, ainda que dentro dos limites impostos à jurisdição, o direito para os casos atuais e futuros.

Assim, da mesma forma que a institucionalização pelo código peculiar do direito não confere ao legislador legitimidade suficiente à flutuação do conteúdo do direito positivo, esse mesmo fenômeno se mostra insuficiente frente a um Judiciário que passa, à sua própria maneira, também a ditar o tom dessas flutuações.

Em uma tentativa de síntese, focada exclusivamente sobre a atividade jurisdicional, e que já anuncia o problema que se propõe a enfrentar, o direito não legitima a si próprio. Normas positivadas não podem ser invocadas como argumento último de legitimidade sobre uma atividade capaz de modificar o sentido do direito positivo.

Por isso, não parece adequado o papel solitário e autossuficiente do juiz Hércules, destacado em Ronald Dworkin, capaz de resolver qualquer caso por meio da correta articulação dos princípios. Admitida a inadequação, parece fértil o campo para a articulação com as ideias filosóficas que se avolumaram a partir da virada linguistica.

Especialmente sedutora se apresenta, neste campo, a abordagem de Junger Habermas acerca de sua ética do discurso e de sua teoria do agir comunicativo, especialmente por sua articulação com o princípio da Democracia, a qual será abordada nos dois primeiros capítulos deste trabalho.

Então, a partir das bases firmadas, buscar-se-á, no terceiro e último capítulo, definir se é plausível sua utilização para fundamentar a legitimidade da acentuada atividade criativa da jurisdição constitucional.

\section{A PROPOSTA DISCURSIVA DE HABERMAS}

Habermas propõe, ao longo de toda sua obra, o abandono do paradigma da consciência em prol do paradigma da comunicação, mais precisamente, do paradigma da comunicação racional. Para o Autor alemão, o processo de reificação que rege o sistema capitalista não pode ser confundido com as ações dos atores sociais. Nesta, ao contrário do que propunha o paradigma da racionalidade, pode existir espontaneidade a partir da comunicação.

O caráter social e histórico da estrutura da consciência demonstrado por Hegel, a natureza como campo da mente proposto por Marx e o inconsciente desvelado por Freud desmistificaram as forças do pensamento filosófico e a esperança de se localizar uma filosofia primeira.

Como assinala José Marcelino de Rezende Pinto, citando Habermas:

[...] eu pretendo arguir que uma mudança de paradigma para o da teoria da comunicação tornará possível um retorno à tarefa que foi interrompida com a crítica 
da razão instrumental; e isto nos permitirá retomar as tarefas, desde então negligenciadas, de uma teoria crítica da sociedade[.. ${ }^{3}$.

Ao contrário do que se observa na filosofia da consciência, o que é paradigmático para a racionalidade comunicativa

[...] não é a relação de um sujeito solitário com algo no mundo objetivo que pode ser representado e manipulado, mas a relação intersubjetiva, que sujeitos que falam e atuam, assumem quando buscam o entendimento entre si, sobre algo. Ao fazer isto, os atores comunicativos movem-se por meio de uma linguagem natural, valendo-se de interpretações culturalmente transmitidas e referem-se a algo simultaneamente em um mundo objetivo, em seu mundo social comum e em seu próprio mundo subjetivo $[\ldots]^{4}$.

O novo paradigma proposto por Habermas desloca da relação sujeito - objeto a possibilidade única de um conhecimento capaz de atingir a um resultado válido. Na racionalidade comunicativa, as relações intersubjetivas, carregadas de suas experiências, seu arcabouço cultural, sua forma de ver o mundo, desvelam novos horizontes de saber que o objeto, em sua fria existência, não poderia revelar.

Mas nesse deslocamento de paradigma Habermas não propõe que a comunicação capaz de desvelar esses novos horizontes seja materializada em todo e qualquer tipo de conversa ou discurso. Pelo contrário. A forma comunicativa capaz de legitimar novas configurações de conhecimento está consubstanciada na teoria do agir comunicativo, que se desenvolve a partir da teoria dos atos de fala, reivindicando uma série de pressupostos que permitam aos sujeitos envolvidos o exercício de uma comunicação racional, procedimental, calcada no mútuo entendimento, em busca de um consenso, ou, pelo menos, na equalização dos dissensos.

\subsection{Os atos de fala}

Em Habermas, a unidade fundamental do discurso é o ato de fala, assim entendido, a partir de Austin, como a menor sequência verbal das emissões de um falante, dirigida, pelo menos, a um receptor, ou ouvinte, capaz, igualmente, de outro ato de fala. $O$ ato de fala, portanto, cria uma relação entre falante e ouvinte, com vistas ao entendimento de seu conteúdo.

$\mathrm{O}$ ato de fala é espécie dos atos possíveis de comunicação. Contudo, para o desenvolvimento de sua teoria da ação comunicativa, Habermas concentra-se exclusivamente nos atos de comunicação que possam ser identificados como elementos de um discurso (em sentido amplo): os atos de fala 5 .

\footnotetext{
${ }^{3}$ HABERMAS, J. Teoria do Agir Comunicativo. Vol. I. Tradução: Fabio Beno Siebenneicheler. São Paulo: Editora Martins Fontes, 2012. p. 81.

${ }^{4}$ PINTO, José Marcelino de Rezende. A teoria da ação comunicativa de Jürgen Habermas: conceitos básicos e possibilidades de aplicação à administração escolar. Paidéia (Ribeirão Preto), Ribeirão Preto , n. 8-9, p. 77-96, Aug. 1995. Disponível em $<$ http://www.scielo.br/scielo.php?script=sci_arttext\&pid= S0103-863X1995000100007 \&lng=en\&nrm=iso >. Acesso em 21 Nov. 2017.

${ }^{5}$ HABERMAS, Jünger. Racionalidade e Comunicação. Lisboa: Edições 70, 2002. p. 10.
} 
Mas para que os atos de fala sejam travestidos da forma de elementos uma ação comunicativa válida, é necessário que o falante observe alguns pressupostos. Assim, para Habermas, "qualquer pessoa que aja segundo uma atitude comunicativa deve, ao efetuar qualquer tipo de acto de fala, apresentar pretensões de validade universal e supor que estas podem ser defendidas"6.

Para tanto, prossegue Habermas, explicitando as formas como a pretensão de validade pretendida pelo falante deverá se desdobrar no discurso: (a) primeiro, o falante deve se fazer compreensível, ou seja, escolher uma "forma de expressão inteligível"", (b) em segundo lugar, deve pretender expressar suas intenções de maneira verdadeira, sendo digno de confiança dos demais atores da comunicação, demonstrando sinceridade, (c) por fim, deve adotar um discurso correto no que respeita às "normas" e valores fundamentais, pressupostos em uma base reciprocamente reconhecida.

Conjugadas, essas exigências de clareza $^{8}$, verdade, sinceridade e acerto formam o que Habermas denomina de "pretensão de validade", a qual deve estar presente e pressuposta não apenas por um, mas por todos os participantes do ato de comunicação, servindo como ponto de convergência para o reconhecimento intersubjetivo de todos, para a compreensão mútua ${ }^{9}$.

Habermas não aponta a necessidade de uma fase preliminar de discussões a respeito dessas pretensões, bastando que elas sejam aceitas, ainda que tacitamente, pelos falantes. Contudo, qualquer um que se lance a emitir um ato de fala deve estar pronto para demonstrar e defender essas pretensões, caso necessário.

Assim, o agir comunicativo - que se materializa em um processo construído pelo entendimento - parte, ele próprio, de um consenso prévio acerca da presença das condições de validade dos atos de fala, ainda que de forma tácita.

\subsection{Agir estratégico e agir comunicativo}

Em sua formulação acerca dos atos de fala, Austin os classifica em três formas: os atos locutórios, os atos ilocutórios e os atos perlocutórios ${ }^{10}$. O ato locucionário pode ser resumido a um dizer algo, sem maiores preocupações quanto às intenções do falante e aos efeitos sobre outras pessoas. Por ser um ato mais simples, não possui grande atenção na obra de Habermas.

Adiando-se, propositalmente, a análise dos atos ilocutórios para o final, os atos perlocutórios podem ser entendidos como os efeitos, gerados sobre o interlocutor, por aquilo que foi expressado pelo falante. Esses efeitos podem encerrar uma persuasão, um convencimento, um constrangimento

\footnotetext{
${ }^{6}$ lbid. p. 12.

7 HABERMAS, Jünger. Racionalidade e Comunicação. Lisboa: Edições 70, 2002 p 12.

${ }^{8}$ Nas formulações posteriores de sua teoria, Habermas deslocou a inteligibilidade ou a clareza para um momento anterior à verificação dos demais pressupostos, já que, se a emissão não puder ser compreendida, sequer é possível cogitar de um ato de fala relevante no agir comunicativo.

${ }^{9}$ HABERMAS, Jünger. Racionalidade e Comunicação. Lisboa: Edições 70, 2002. p. 97.

${ }^{10}$ AUSTIN, J.L. Quando Dizer é Fazer. Porto Alegre: Artes Médicas, 1990
} 
etc. ${ }^{11}$. Em suma, os efeitos perlucutórios estão associados à intenção do falante no momento em que faz um proferimento.

Quando os atos de fala sejam previamente orientados a uma determinada finalidade por parte do emissor de uma proposição, resta anulada a possibilidade de se agir comunicativamente, já que caem por terra as pretensões de validade inerentes a um ato de fala emitido nesse contexto, não mais forjados como componente do entendimento procedimental.

Estar-se-á, nesses casos, diante do que Habermas denomina de agir estratégico:

Por certo, sujeitos que agem estrategicamente supõe entre si que, na medida em que decidem racionalmente, eles baseiam suas decisões em opiniões que eles mesmos tomam por verdadeiras. Mas os valores de verdade pelos quais cada um deles se orienta do ponto de vista de suas próprias preferências e objetivos não se transformam em pretensões de verdade, talhadas para um reconhecimento subjetivo ${ }^{12}$.

Por isso, no contexto da ação comunicativa, Habermas confere especial importância à força ilocutória dos atos de fala, também analisada por Austin, no sentido de que falar é o mesmo que agir. Assim, "ao fazermos uma promessa, uma garantia ou um aviso, executamos simultaneamente uma acção com as frases correspondentes: tentamos fazer uma promessa, apresentar uma garantia ou emitir aviso (ou seja, fazemos as coisas dizendo alguma coisa)"13.

Para Habermas, a verdadeira força ilocutória dos atos de fala não reside em se tratar de uma forma particular de ação, mas sim em seu poder generativo, consistente no poder que possui o falante, ao emitir um ato de fala poder "influenciar o ouvinte de tal forma que este possa estabelecer uma relação interpessoal com ele"14.

O aspecto ilocutório ou ilocucionário, pois, é que fornece o caráter performativo aos atos de fala, transformando-os verdadeiramente em ação, materializada pela intenção ou pela força que o falante confere a seu ato de fala.

Habermas, evidentemente, não ignora que o ato ilocutório contém em si sempre um ato perlocutório. Contudo, no contexto do agir comunicativo, a colaboração para o entendimento e a busca do consenso (enfim, a força ilocucionária), será preponderante em relação às eventuais finalidades do falante.

Isso não significa a ilusão de que o sujeito, na ação comunicativa, esteja completamente despido de sua individualidade, mas seus fins singulares devem ser buscados sob condições que possam ser partilhadas por todos, com a coordenação dos planos de ação e a harmonização das pretensões individuais.

Contudo, embora rejeitando a formulação de Austin, Habermas apontará que a forma padrão dos atos de fala não se restringem à sua componente ilocutória. Além desta, deve estar presente uma componente proposicional, que será, em síntese, o seu conteúdo ${ }^{15}$ :

${ }^{11}$ CASTIM, Fernando. John Austin e os atos de fala. In Revista Ágora Filosófica da Universidade Católica de Pernambuco. Ano 17. n 1. jan-jun 2017. Disponível em www.unicap.br/ojs/index.php/agora/article/download/1004/865. Acesso em 15 nov. 2017.

12 Verdade e justificação: ensaios filosóficos. São Paulo: Loyola, 2004. p. 124.

${ }^{13}$ HABERMAS, Jünger. Racionalidade e Comunicação. Lisboa: Edições 70, 2002. p. 57.

14 Ibid. p. 58.

${ }^{15}$ HABERMAS, Jünger. Racionalidade e Comunicação. Lisboa: Edições 70, 2002. p. 66. 
A esta dupla estrutura do discurso está ligada uma característica basica da linguagem: a sua inerente reflexividade. (...) Ao preencherem a dupla estrutura do discurso, os participantes de um dado diálogo comunicam simultaneamente a dois níveis, combinando a comunicação de um conteúdo com a metacomunicação (comunicação acerca do sentido no qual o conteúdo comunicado é usado) ${ }^{16}$.

Por isto, não há representação desta componente em atos não linguísticos, já que, nestes casos, a proposição estará embutida em um conjunto pressuposto de normas aceitas pelas partes. Apenas os atos linguísticos, pois, são objetos relevantes para a teoria habermasiana.

\subsection{Comunicação e racionalidade}

A identificação das duas componentes pertencentes ao discurso, ilocucionária e proposicional, permite que se identifique a dupla estrutura dos discursos, ou seja, permite sua separação em dois níveis distintos de comunicação, nos quais os participantes deverão chegar a um acordo:

Distinguiríamos, então, (i) o nível de intersubjectividade, no qual falante e ouvinte, através de actos ilocutórios, estabelecem a relação que lhes permite chegar a um entendimento mútuo e (ii) o nível de conteúdo proposicional, acerca do qual pretendem estabelecer um entendimento na função comunicativa especificada em (i). Correspondendo aos aspectos relacional e de conteúdo, do ponto de vista em que todas as expressões podem ser analisadas, existem então nos actos de fala (na forma-padrão) as componentes ilocutória e proposicional ${ }^{17}$.

Dentro desses dois níveis de comunicação, Habermas busca identificar as condições para que a comunicação não apenas ocorra, mas para que ocorra racionalmente.

$\mathrm{Na}$ situação comunicacional criada por Habermas, os atores poderão assumir os papeis de falantes e de ouvintes, e a capacidade de reconhecimento intersubjetivo da pretensão de validade necessária a dar legitimidade ao processo comunicativo é que definirá o sucesso ilocucionário de um ato de fala. Afinal, "entender-se é um processo de obtenção de um acordo entre sujeitos linguisticamente e interativamente competentes"18. Assim:

O sentido ilocucionário de um proferimento ["p"] não é de que o ouvinte [“O”] tome conhecimento da opinião ou intenção de " $\mathrm{F}$ ", mas o de que ele cheque à mesma concepção de " $F$ " (ou de que leva a sério o anúncio de " $F$ "). Para que $F$ alcance a sua meta ilocucionária, não basta que "O" conheça as condições de verdade (ou de sucesso de "p"); "O" também deve compreender o sentido ilocucionário de afirmações (ou de declarações de intenção), e, se possível, aceitar também as condições de validade correspondentes ${ }^{19}$.

Assim, um acordo alcançado comunicativamente terá, necessariamente, uma base racional, na medida em que não poderá ser imposto por qualquer das partes, o que difere de um acordo

\footnotetext{
${ }^{16}$ Ibid. p. 67-68.

${ }^{17}$ HABERMAS, Jünger. Racionalidade e Comunicação. Lisboa: Edições 70, 2002. p. 67.

18 Id.Teoria do Agir Comunicativo.Vol. I.São Paulo:Editora Martins Fontes, 2012. p. 368.

${ }^{19}$ HABERMAS, Jünger. Verdade e justificação: ensaios filosóficos. São Paulo: Loyola, 2004. p. 124.
} 
supostamente comum na ação comunicativa, no qual já se parte de uma forma hipotética de acordo, obliterando as exigências de competência concernentes à pretensão de validade ${ }^{20}$.

Por isso, a partir da inexistência de um referencial teórico absoluto evidenciado pelo deslocamento paradigmático, o que torna melhor um argumento, face a outro, é "a sonoridade de suas razões ${ }^{21 "}$, estando a racionalidade dessas razões no fato de suas pretensões de validade serem suscetíveis a críticas, por meio de procedimentos intersubjetivamente reconhecidos.

Assim, para Habermas:

[...] Racionalidade comunicativa possui conotações que em última instância remontam à experiência central da capacidade de anuir sem coações e gerar consenso que tem uma fala argumentativa, na qual os diversos participantes superam a subjetividade inicial de seus respectivos pontos de vista e em razão de uma comunidade de convicções racionalmente motivada asseguram a racionalidade do mundo objetivo e a intersubjetividade do contexto em que se desenvolvem suas vidas ${ }^{22}$.

Em termos mais simples, a racionalidade comunicativa surge na figura de um agente que se entende, com alguém, a respeito de algo ${ }^{23}$. O dissenso, por seu turno, surge a partir dessas mesmas bases racionais quando um dos atores do agir comunicativo questiona uma das pretensões de validade do ato de fala, situação em que a questão é problematizada no interior da comunicação, mas agora por meio do discurso. Para o Autor alemão:

A ideia de que a ordem social deveria produzir-se pelo caminho de processos de formação do consenso parece trivial à primeira vista. No entanto, tão logo nos lembramos de que qualquer acordo obtido comunicativamente depende de uma tomada de posição em termos de sim/não com relação a pretensões de validez criticáveis, salta aos olhos a inverossimilhança de tal ideia. A dupla contingência a ser absorvida por cada formação de interação assume, no caso do agir comunicativo, a forma especialmente precária de um risco de dissenso, sempre presente e embutido no próprio mecanismo de entendimento; e todo dissenso implica grandes custos ${ }^{24}$.

A isso tudo Habermas antecipa o que denomina de "situação ideal de fala", entendida "como uma situação em que as comunicações não podem ser obstruídas pelas contigências externas, ou mesmo pelas coações que são derivadas da própria estrutura da comunicação"25. Por isso, quem participa de argumentações com seriedade deve observar a preexistência desses pressupostos, os quais, se não levados em conta pelos participantes da argumentação, acarretarão num nítido paradoxo, já que a situação ideal de fala surge como uma forma de vida pressuposta nas estruturas da comunicação, sem a qual já se tem ciência plena de que os atos de fala dirigidos não poderão servir à obtenção de um consenso legítimo, o qual, repita-se, apenas será possível quando o assentimento ou a discordância entre os participantes for conduzida unicamente pela força do melhor argumento.

20 Id. Teoria do Agir Comunicativo. Vol. I. São Paulo: Editora Martins Fontes, 2012. p. 368.

${ }^{21}$ PINTO, José Marcelino de Rezende. A teoria da comunicação. Acesso em 21 Nov. 2017.

${ }^{22}$ HABERMAS, Jünger.Teoria do Agir Comunicativo.Vol. I.São Paulo:Editora Martins Fontes, 2012. p. 367.

${ }^{23}$ Id. Racionalidade e comunicação, p. 137.

${ }^{24}$ Id. Pensamento Pós-Metafísico. Tempo Brasileiro: Rio de Janeiro, 1990. p. 82.

25 BOTELHO, M. C. A Legitimidade da Jurisdição Constitucional no Pensamento de Jürgen Habermas. São Paulo: Editora Saraiva, 2010.

Revista do Direito [ISSN 1982-9957]. Santa Cruz do Sul, v. 1, n. 54, p. 99-119, jan./abr. 2018. https://online.unisc.br/seer/index.php/direito/index 


\section{AGIR COMUNICATIVO E O DIREITO}

\subsection{O Direito e o mundo da vida}

Habermas compartilha, para fins teóricos, da ideia de uma situação hipotética ideal - e inicial - da sociedade, ilustrada por Durkheim, na qual os processos de comunicação ocupam um papel quase nulo, em face da perfeita integração e harmonia existente entre as elementos da massa social, em que não há destaque para as subjetividades, porque homogêneas, em uma condição de estabilidade garantida pelos domínios da religião.

Nesse cenário ideal, os elementos estruturais que formarão o que Habermas denominará "mundo da vida" (cultura, sociedade e personalidade), ainda não se diferenciaram, mas permanecem integrados sob o amálgama da religião (elemento de integração social).

O passar do tempo e o processo de secularização que marca a modernização das sociedades conferem, contudo, peso cada vez mais acentuado aos processos comunicativos de se chegar a um entendimento. Abre-se, com isso, caminho para que as crenças que compõe o "mundo da vida" sejam deslocadas para o centro dos debates e, já refletidas, nele reinseridas. Ilustra-se, assim, um processo de racionalização do "mundo da vida", que passa, cada vez mais, a ser preenchido por conteúdos reflexivos (firmados após um processo comunicativo).

É nesse contexto que se acentua o objetivo da ação comunicativa como instrumento destinado à integração social, a qual já não mais pode estar fundamentada no sagrado.

Habermas, portanto, não ignora, nos processos de comunicação, os fatores sociais e culturais que permeiam, quase que de forma inconsciente, os discursos de qualquer sujeito. A esses fatores, os quais Habermas designará como "mundo da vida", cabem o papel de pano de fundo a direcionar os fundamentos expostos em qualquer processo de argumentação:

[...] os atores estão sempre se movendo dentro do horizonte do seu mundo da vida, eles não podem se colocar de fora dele. Como intérpretes, eles próprios pertencem ao mundo da vida, por meio de seus atos de fala, mas não podem se referir a "algo no mundo da vida" da mesma forma que podem fazer com fatos, normas e experiências subjetivas. ${ }^{26}$

Esse mundo da vida complexo, em Habermas, será composto de três estruturas, uma objetiva, uma social e uma subjetiva. São as componentes estruturais da (a) cultura ("estoque de conhecimento do qual os atores suprem-se de interpretações quando buscam a compreensão sobre algo no mundo"), da (b) sociedade ("ordens legítimas através das quais os participantes regulam suas relações no grupo social") e da (c) pessoa ("competências que tornam um sujeito capaz de falar e agir, ou seja, de compor sua própria personalidade") $)^{27}$.

A correlação direta entre ação comunicativa e mundo da vida surge, em Habermas, por caber àquela a reprodução das estruturas simbólicas do mundo da vida (cultura, sociedade, pessoa). Assim, ao longo de toda sua obra, Habermas dará ao termo "mundo da vida" função central na

${ }^{26}$ HABERMAS, Jürgen. Teoria do Agir Comunicativo: racionalidade da ação e racionalização social. Vol. 2. Tradução: Fabio Beno Siebenneicheler. São Paulo: Martins Fontes, 2012. p. 126.

${ }^{27}$ Ibid. p. 172.

Revista do Direito [ISSN 1982-9957]. Santa Cruz do Sul, v. 1, n. 54, p. 99-119, jan./abr. 2018. https://online.unisc.br/seer/index.php/direito/index 
coordenação e na estabilização da ação social, capaz de guiar e viabilizar uma comunicação improvável. Será o "mundo da vida", pois, a um só tempo, (a) um pano de fundo do agir comunicativo, (b) um horizonte para situações de fala e (c) uma fonte de interpretações a auxiliar os autores da comunicação 28 .

O "mundo da vida" será, então, mais que um simples pano de fundo, um contexto sempre implícito, insuscetível ele próprio de tematização, onde se formam os processos de entendimento em busca de um consenso, e onde os sujeitos se movimentam, tornando-se seus intérpretes. Será um complemento do agir comunicativo, sendo reproduzido pela própria ação comunicativa. Como ressalta Marcos César Botelho29:

O mundo da vida é, por assim dizer, o lugar transcendental em que falante e ouvinte se enconmtram; em que podem plantear-se reciprocamente a pretensão de que suas emissões concordam com o mundo (com o mundo objetivo, com o mundo subjetivo e com o mundo social), e em que podem criticar e exibir os fundamentos dessas pretensões de validez, resolver seus dissentimentos e chegar a um acordo.

Mais adiante, ressaltando a relação entre o mundo da vida e o agir comunicativo, prossegue 0 autor ${ }^{30}$ :

Habermas afirma que a ação comunicativa é mais que um processo de entendimento, já que, ao se entender sobre algo no mundo, os atores sociais estão participando de interações simultâneas mediante as quais desenvolvem, confirmam e renovam seu pertencimento aos grupos sociais. Em outras palavras "as ações comunicativas não são somente processos de interpretação em que o saber cultural queda exposto ao "teste do mundo"; significam ao mesmo tempo processos de interação social e de socialização".

A forma de expressão desse mundo da vida, contudo, sofre reformulação profunda no pensamento habermasiano a partir de seus estudos em "Direito e Democracia: entre facticidade e validade".

Inobstante o papel integrador social da linguagem no bojo do agir comunicativo, Habermas assume, em suas obras posteriores que, em sociedades complexas, modernas, descentralizadas e dessacralizadas, essa linguagem não possui força normativa suficiente a fazer as vezes de amálgama entre os anseios difusos de uma sociedade plural.

Surge, então, a dependência do Direito para o exercício desse papel.

Em sociedades tão antagônicas e difusas somente o Direito afigura-se capaz de estabilizar as questões problematizadas. Afinal, é o Direito "que se apresenta com pretensão à fundamentação sistemática, à interpretação obrigatória e à imposição"31. Em outras palavras, o Direito institucionaliza as pretensões de validade que surgem na esfera pública, com efeito impositivo a todos:

${ }^{28}$ Silva Miranda, Maressa da, O mundo da vida e o Direito na obra de Jürgen Habermas. Prisma Jurídico 2009, 8. Disponível em:<http://www.redalyc.org/articulo.oa?id=93412810006> ISSN 16774760>. Acesso em 16 nov. 2017.

29 BOTELHO, M. C. A Legitimidade da Jurisdição Constitucional no Pensamento de Jürgen Habermas. São Paulo: Editora Saraiva, 2010.

30 BOTELHO, M. C. A Legitimidade da Jurisdição Constitucional no Pensamento de Jürgen Habermas. São Paulo: Editora Saraiva, 2010.

${ }^{31}$ HABERMAS, Jünger. Direito e Democracia: entre facticidade e validade, vol. 1. Tempo Brasileiro: 2000. p. 110.

Revista do Direito [ISSN 1982-9957]. Santa Cruz do Sul, v. 1, n. 54, p. 99-119, jan./abr. 2018. https://online.unisc.br/seer/index.php/direito/index 
É verdade que a linguagem coloquial forma um horizonte da compreensão; em princípio ela é capaz de traduzir tudo em todas as linguagens. Porém, ela é incapaz de operacionalizar eficientemente para todos os destinatários suas mensagens endereçadas ao comportamento. Para traduzi-las nos códigos especiais, ela depende do direito, o qual tem contato com o dinheiro e o poder administrativo ${ }^{32}$.

E continua:

O direito funciona como uma espécie de transformador. Mensagens normativas só conseguem circular em toda a amplidão da sociedade através da linguagem do direito; sem a tradução para o código do direito, que é complexo, porém aberto tanto ao mundo da vida como ao sistema, estes não encontrariam eco nos universos de ação dirigidos por meios .

A consequência da centralidade do Direito como medium destinado à integração social é a busca, por Habermas, da legitimidade desse mesmo Direito.

Não basta aqui, como outrora parecia suficiente, que o Direito esteja legitimado por autoridades ou mesmo por derivação de uma ordem moral pré-definida e abstrata. Como dirá Habermas, "O direito não consegue o seu sentido normativo pleno per se através de sua forma, ou através de um conteúdo moral dado a priori, mas através de um procedimento que instaura o direito, gerando legitimidade" 33 .

Identifica-se, por isso, um paradoxo na tentativa de se fundamentar o direito em sua própria legalidade, afinal, também os direitos políticos, garantidores da participação dos cidadãos na vida pública, possuem, eles próprios, a estrutura inerente ao direito, portadores de um conteúdo contingente e dotados de coercibilidade ${ }^{34}$.

\subsection{Direito e moral}

A legitimidade do Direito, assim, não se localiza em seu conteúdo, nem tampouco em sua pura e simples institucionalização, o que torna especialmente relevante a investigação acerca do papel da moral e da democracia na legitimação do código jurídico.

Habermas caminha junto a Kant quando compreende uma relação entre o direito e a moral. Contudo, dele afasta-se radicalmente ao afirmar que o princípio da democracia não pode ser subordinado ao princípio da moral, como ocorre na concepção kantiana ${ }^{35}$.

Segundo Habermas, não existe uma relação de subordinação entre o direito e a moral, mas uma relação de complementariedade. No pensamento pós-metafísico, tanto o direito, quanto a moral, diferenciam-se da eticidade tradicional, mas portam-se como dois tipos normativos distintos, que operam lado a lado ${ }^{36}$.

\footnotetext{
32 Ibid. p. 82.

${ }^{33}$ HABERMAS, Jünger. Direito e Democracia: entre facticidade e validade, vol. 1. Tempo Brasileiro: 2000. p. 172.

34 Ibid. p. 115.

35 Ibid. p. 113.

${ }^{36}$ HABERMAS, Jünger. Direito e Democracia: entre facticidade e validade, vol. 1. Tempo Brasileiro: 2000. p. 139.
} 
Assim, inobstante refiram-se ao mesmo problema - ordenação - o fazem sob enfoques distintos, sendo a moral, nos dizeres de Habermas "uma forma do saber cultural, ao passo que o direito adquire obrigatoriedade também no nível institucional". Assim, "o direito não é apenas um sistema de símbolos, mas também um sistema de ação"37.

Como normas de ação que são, tanto o direito quanto a moral podem ser fundamentados imparcialmente por meio do princípio do discurso ("D"), segundo o qual: "são válidas as normas de ação às quais todos os possíveis atingidos poderiam dar o seu assentimento, na qualidade de participantes de discursos racionais" 38 .

São "discursos racionais", por seu turno, todo agir voltado a um entendimento procedimental, pois - sob as condições já analisadas na primeira parte deste trabalho, relativas às pretensões de validade, à força ilocucionária dos atos de fala e à liberdade de movimento dos agentes da comunicação no "mundo da vida".

Assim, tanto a moral quanto o direito poderiam ser fundamentados por meio de um princípio de bases mais amplas, o que seria bastante para demonstrar sua cooriginalidade e, portanto, a inexistência de subordinação entre ambos.

No entanto, como já dito, o abandono da fundamentação vertical não afasta o conteúdo moral do direito. A legitimação democrática de qualquer instância normativa se baseia não mais em uma moral universal abstrata, mas na esfera privada de cada agente moral.

Assim, Habermas não propõe a completa ruptura entre o direito e a esfera moral, tal como se encontra na formulação purista de Kelsen, apenas rejeita a ideia de autoridade universal, como era o papel do primado moral da liberdade em Kant. Formula o Filósofo alemão:

É possível formular este problema da seguinte maneira: de um lado, os fundamentos morais do direito positivo não podem ser explicados em termos de um direito racional superior. De outro lado, porém, esses fundamentos não podem ser liquidados sem deixar nenhum vestígio, pois isso privaria o direito do momento essencial da indisponibilidade que habita nele. A partir daí, é preciso mostrar como é possível estabilizar, no interior do próprio direito positivo, o ponto de vista moral de uma formação imparcial do juízo e da vontade. O fato de determinados princípios morais do direito racional terem sido positivados como conteúdos do direito constitucional não basta para satisfazer esta exigência. Pois trata-se precisamente da contingência dos conteúdos de um direito modificável arbitrariamente. Por isso, eu gostaria de retomar a tese desenvolvida na primeira aula, segundo a qual a moralidade embutida no direito positivo possui a força transcendente de um processo que se regula a si mesmo e que controla sua própria racionalidade ${ }^{39}$.

No lugar da racionalidade pura, abstrata e vertical do imperativo moral da liberdade, o direito para Habermas deve ser pensado na perspectiva da realidade democrática, na qual a legitimidade das normas passa pela discussão pública não apenas no nível da representatividade política, mas também no nível da participação ativa do cidadão no debate público.

Nesse contexto, a moral do Direito em Habermas se revela a partir da prática discursiva, o que resta claro quando afirma que a "legalidade tem que extrair sua legitimidade de uma

\footnotetext{
37 Ibid. p. 141.

38 lbid. p. 142.

39 HABERMAS, Jünger. Direito e Democracia: entre facticidade e validade, vol. 2. Tempo Brasileiro: 2000. p. 243
}

Revista do Direito [ISSN 1982-9957]. Santa Cruz do Sul, v. 1, n. 54, p. 99-119, jan./abr. 2018. https://online.unisc.br/seer/index.php/direito/index 
racionalidade procedimental com teor moral. Esta racionalidade resulta do entrelaçamento entre dois tipos de 'processos', pois argumentações morais são institucionalizadas com o auxílio de meios jurídicos ${ }^{40 "}$

E isso é possível justamente pelas distinções inicialmente estabelecidas entre o direito e a moral, sobretudo quanto às suas esferas de atuação. Na medida em que a moral é uma forma do saber cultural, ela acaba por se institucionalizar dentro de um processo comunicativo no qual os falantes, por seus atos de fala e a partir das estruturas do mundo da vida intersubjetivamente compartilhado, transportam essa moral para o procedimento legitimador do direito.

Assim, para Habermas, as normas jurídicas não são mais produtos de uma racionalidade abstrata e desconexa do mundo, mas sim produtos de consensos de ordem argumentativa, baseados na ética do discurso.

\subsection{Democracia Procedimental}

O princípio do discurso, após assumir forma jurídica, ou seja, após sua institucionalização, adquire a roupagem do princípio da democracia ${ }^{41}$, lastreado na ideia de que o direito deve emanar do povo, e de que o cidadão que participa da formação discursiva do direito na esfera pública será também o cidadão que será conformado por esse mesmo direito:

A ideia básica é a seguinte: o princípio da democracia resulta da interligação que existe entre o princípio do discurso e a forma jurídica. Eu vejo esse entrelaçamento como uma gênese lógica de direitos, a qual pode ser reconstruída passo a passo. Ela começa com a aplicação do princípio do discurso ao direito a liberdades subjetivas de ação em geral - constitutivo para a forma jurídica enquanto tal - e termina quando acontece a institucionalização jurídica de condições para um exercício discursivo da autonomia política, a qual pode equipar retroativamente a autonomia privada, inicialmente abstrata, com a forma jurídica. Por isso, o princípio da democracia só pode aparece como núcleo de um sistema de direitos. A gênese lógica desses direitos forma um processo circular, no qual o código do direito e o mecanismo para a produção de direito legítimo, portanto o princípio da democracia, se constituem de modo cooriginário ${ }^{42}$.

Habermas identificará, contudo, na formação do próprio código do direito, a partir da aplicação do princípio do discurso, a existência dos direitos fundamentais, determinantes do status das pessoas de direito e garantidores das autonomias privada e pública dos sujeitos enquanto destinatários e autores das leis, sem os quais não se pode pensar em direito legítimo.

Tem-se, em um primeiro momento, sob uma perspectiva teórica e externa, no que tange à autonomia privada, o (a) direito a liberdades subjetivas gerais de ação (direito à maior medida possível de iguais liberdades de ação subjetivas) ${ }^{43}$, (b) do direito à participação da associação

\footnotetext{
40 Ibid.p. 191.

${ }^{41}$ HABERMAS, Jünger. Direito e Democracia: entre facticidade e validade, vol. 1. Tempo Brasileiro: 2000. p. 156.

42 Ibid. p. 158.

${ }^{43}$ Ibid. p. 160.
}

Revista do Direito [ISSN 1982-9957]. Santa Cruz do Sul, v. 1, n. 54, p. 99-119, jan./abr. 2018. https://online.unisc.br/seer/index.php/direito/index 
voluntária de membros do direito (direitos relativos à cidadania) ${ }^{44}$ e (c) do direito à postulação ou à proteção jurídica individual (livre acesso a tribunais independentes e efetivos) ${ }^{45}$.

Estabelecidos, sob o teste do princípio do discurso, os direitos mínimos reciprocamente reconhecidos para a regulação da convivência dos sujeitos, estes (sujeitos) passam a ser aptos, por si próprios, à aplicação do princípio do discurso, assumindo o papel de autores de sua própria ordem jurídica, sob os limites do código preestabelecido do direito, por meio dos direitos fundamentais "à participação, em igualdade de chances, em processos de formação da opinião e da vontade"46.

Neste contexto, transporta-se para o bojo do processo legislativo democrático a possibilidade de as razões que subjazem à fundamentação das leis serem expostas e confrontadas com base em discursos racionais, sujeitos ao preenchimento das pretensões de validade, em um ambiente no qual o entendimento é construído a partir da sonoridade dos melhores argumentos.

Assim, a legitimidade do direito perpassa, dentro da prática discursiva, pelos direitos fundamentais e pela soberania popular, os quais, unidos, garantem a existência própria de um Estado Democrático de Direito ${ }^{47}$. Em síntese, "a substância dos direitos humanos insere-se, então, nas condições formais para a institucionalização jurídica desse tipo de formação discursiva da opinião e da vontade, na qual a soberania do povo assume figura jurídica"48.

Para Habermas, então, a legitimidade do processo de criação do direito dependerá da existência de processos democráticos que garantam a participação comunicativa de todos os cidadãos, na condição de pessoas livres e iguais, com ampla possibilidade de intervenção discursiva.

No bojo dessa formação procedimental do direito, lastreada nos direitos fundamentais garantidores da autonomia privada dos cidadãos, nos direitos políticos de participação e no reconhecimento da soberania popular, propiciar-se-á a concretização político-racional da opinião e da vontade, sem perder de vistas, evidentemente, que todas essas interações devem ocorrer em espaços e sob as condições previamente criadas pelo próprio direito.

É certo que a teoria habermasiana acerca do direito desbrava muitos outros aspectos em direção à solução do conflito entre a validade e a facticidade do código jurídico, contudo, dentro dos limites inerentes ao presente trabalho e no que concerne a seus objetivos, as considerações até aqui expostas mostram-se suficientes para que se avance no tema.

\section{AGIR COMUNICATIVO E LEGITIMIDADE DA JURISDIÇÃO CONSTITUCIONAL}

\footnotetext{
44 Ibid. p. 161

45 Ibid. p. 162.

4646 HABERMAS, Jünger. Direito e Democracia: entre facticidade e validade, vol. 1. Tempo Brasileiro: 2000. p. 159.

47 Ibid. p. 170.

${ }^{48}$ Ibid. p. 139
}

Revista do Direito [ISSN 1982-9957]. Santa Cruz do Sul, v. 1, n. 54, p. 99-119, jan./abr. 2018. https://online.unisc.br/seer/index.php/direito/index 
A transposição do pensamento habermasiano acerca da produção do direito para o campo da jurisdição aparece adequada quando se dá conta do papel criativo assumido, modernamente, por essa atividade do Estado tradicionalmente guiada para a aplicação da lei.

Antes de se prosseguir, contudo, é válido pontuar a bem localizada preocupação de Habermas no sentido de que, a prática interpretativa construtiva, portanto criativa, desenvolvida e enfeixada no exercício argumentativo, não deve permitir que a justiça lance mão de competências legisladoras ${ }^{49}$, o que torna especialmente delicado, na visão do autor, a fundamentação de um órgão jurisdicional habilitado, por exemplo, ao controle abstrato de normas.

As pretensões deste estudo, contudo, não visam a questionar ou justificar a atribuição das competências das cortes constitucionais, mas a propor a valorização de um proceder democrático que enxergue nessa atividade uma aproximação - fática e indiscutível - com os caracteres da função legislativa, com vistas à garantia - ou ao reforço - de sua legitimidade.

Como parece alertar o próprio Habermas ${ }^{50}$ :

Hoje as matérias que necessitam de regulamentação são de tal forma que não podem ser regulamentadas ex ante com suficiente precisão pelo legislador político. Nestes casos, à administração e à justiça competem tarefas de concretização e desenvolvimento do direito que exigem mais deliberações e debates concernentes mais à fundamentação das normas que à aplicação delas.

Neste contexto, esclarece que "a tensão entre facticidade e validade, imanente ao direito, manifesta-se na jurisdição como tensão entre o princípio da segurança jurídica e a pretensão de tomar decisões corretas" 51 .

O deslocamento do paradigma liberal para o Estado de bem estar social rompeu com a lógica até então vigente para a separação dos poderes do Estado, na qual os projetos sociais atinentes ao presente e ao futuro estavam restritos à atuação legislativa, guardando-se para o Judiciário uma atuação ligada à conformação com o passado, restrito às decisões do legislador político ${ }^{52}$.

Nesse novo paradigma, como já se argumentou no decorrer deste trabalho, ocorre a materialização do direito, sobretudo por meio da implementação de programas políticos finalísticos, trazendo em si uma inexorável moralização, capaz de alterar substancialmente a lógica de sua aplicação.

Nesse contexto, "orientada por normas fundamentais, a jurisprudencia precisa voltar seu olhar, normalmente dirigido para a história institucional da ordem jurídica, para problemas do presente e do futuro" 53 .

Tomados como "principios de uma ordem jurídica geral"54, os direitos fundamentais irradiam

\footnotetext{
49 HABERMAS, Jünger. Direito e Democracia: entre facticidade e validade, vol. 1. Tempo Brasileiro: 2000. p. 297.

50 BOTELHO, M. C. A Legitimidade da Jurisdição Constitucional no Pensamento de Jürgen Habermas. São Paulo: Editora Saraiva, 2010.

${ }^{51}$ HABERMAS, Jünger. Direito e Democracia: entre facticidade e validade, vol. 1. Tempo Brasileiro: 2000. p. 245.

5252 HABERMAS, Jünger. Direito e Democracia: entre facticidade e validade, vol. 1. Tempo Brasileiro: 2000. p. 305.

53 Ibid. p. 306.

${ }^{54}$ Ibid. p. 307. A expressão é do Tribunal Constitucional Alemão.
} 
seus efeitos para todas as esferas do direito, estruturando todo o sistema de regras e exigindo atuações positivas do Estado, como uma grande teia jurídica de ação e proteção, o que torna claro o diagnóstico no sentido de que "existe uma mudança de conceitualização dos direitos fundamentais, que se reflete na jurisprudencia constitucional"55.

Esse movimento parece reclamar bases de legitimação tão rigorosas quanto aquelas que se espera da própria formação do direito, sobretudo na esfera da jurisdição constitucional, no papel dos Tribunais no controle de constitucionalidade das normas e mesmo nos diversos institutos de direito processual que fazem com que a norma jurídica individual produzida no bojo de um processo tenha efeitos para além dos limites da relação processual.

Por isso, Habermas parece sugerir um modelo no qual as atribuições concentradas sobre um juiz, solitário e autossuficiente, como se mostra em Dworkin, sejam partilhadas no interior de uma comunidade ideal de fala, metáfora central de seu pensamento. Para Habermas: "é possível ampliar as condições concretas de reconhecimento através do mecanismo de reflexão do agir comunicativo, ou seja, através da prática da argumentação, que exige de todo participante a assunção das perspectivas de todos os outros ${ }^{56 "}$. E ainda:

[...] a pré-compreensão paradigmática do direito em geral só pode colocar limites à indeterminação do processo de decisão iniciado teoricamente e garantir uma medida suficiente de segurança jurídica, se for compartilhada intersubjetivamente por todos os parceiros do direito e se expressar na autocompreensão construtiva para a identidade da comunidade jurídica. [...] $O$ juiz singular tem que conceber sua interpretação construtiva como um empreendimento comum, sustentado pela comunicação pública dos cidadãos. ${ }^{57}$

Habermas sugere, então, que as exigências do ideal político sejam retiradas na personalidade monológica do magistrado para ser deslocada a uma "sociedade aberta dos intérpretes da constituição", apoiado na obra de Peter Häberle.

Nesse contexto, embora o espaço institucionalizado do processo seja imprescindível, ele não pode ser considerado bastante, na medida em que integra, ele próprio, o direito vigente carente de interpretação. Daí a proposta habermasiana no sentido de uma legitimação interna baseada na teoria da argumentação jurídica ${ }^{58}$, a se desenvolver sob os moldes de uma teoria do discurso, em uma relação complementar:

[...] do mesmo modo que os processos democráticos no âmbito da legislação, assim também as ordens dos processos judiciais no âmbito da aplicação do direito, devem compensar a falibilidade e a certeza da decisão que resultam do fato de que os pressupostos comunicativos pretensiosos de discursos racionais só podem ser preenchidos aproximativamente ${ }^{59}$.

Inobstante a reflexão seja válida em termos de processos judiciais em geral, parece mais relevante quando se desloca a análise do problema para o âmbito das cortes constitucionais, uma

\footnotetext{
55 Ibid. p. 307-308.

56 lbid. p. 277.

${ }^{57}$ HABERMAS, Jünger. Direito e Democracia: entre facticidade e validade, vol. 1. Tempo Brasileiro: 2000. p. 278.

58 Ibid. p. 280.

59 Ibid. p. 292.
}

Revista do Direito [ISSN 1982-9957]. Santa Cruz do Sul, v. 1, n. 54, p. 99-119, jan./abr. 2018. https://online.unisc.br/seer/index.php/direito/index 
vez que "na autorização constitucional para o exercício da jurisdição - e tendencialmente em outros tribunais superiores - , de acumula e se agudiza a problemática da indeterminação do direito, à qual já aludimos" 60 .

Contudo, mais uma vez se faz necessário esclarecer a posição de Habermas. Sua crítica ao juiz solipsista e sua proposta discursiva voltada para a atuação jurisdicional não possui alcance tão amplo quanto aquele que o Autor confere à sua análise da legitimidade do direito legislado. Como pondera o próprio Habermas:

Eu mesmo sempre enfatizei que não se pode estabelecer de maneira falaciosa uma relação entre práxis discursiva e procedimento de formação democrática da opinião e da vontade. Além do mais, uma compreensão da jurisdição a partir da teoria do discurso não leva de modo algum à exigência de uma "democratização" dos tribunais. O que resulta do alojamento (apenas postulado) da justiça em uma comunidade de intérpretes que seja aberta e crítica em face da justiça são muito mais exigências crítico-políticas, e apenas no que concerne ao solapamento da divisão funcional de poderes, que já se mencionou acima: quanto mais a justiça recicla o direito, tanto mais energicamente é preciso conclamá-la a justificar-se, não apenas diante de uma opinião pública formada por especialistas, mas sim para fora, perante o fórum dos cidadãos ${ }^{61}$.

Mesmo ao longo da obra "Direito e Democracia", a análise de Habermas acerca da legitimidade da jurisdição constitucional jamais propõe uma transposição de seu modelo de democracia procedimental para os campos do proceso jurisdiccional. A relação se estabelece de modo distinto, defendendo o Autor que as Cortes Constitucionais concentram o papel de proteger e garantir a observancia dessa democracia deliberativa no que tange à produção legislativa, protegendo, por conseguinte, os direitos fundamentais e a soberania popular62.

Evidente que tal relação é assumida a partir de uma teia argumentativa muito mais densa do que a que aquí se expôs, passando especialmente por uma forte crítica à jurisprudencia dos valores, observada na prática do Tribunal Constitucional da Alemanha - e, ousa-se apontar, também no Brasil - e endossada pela Teoria dos Direitos Fundamentais de Robert Alexy. No entanto, as considerações expostas nos capítulos anteriores sobre o modelo habermasiano permite que se avance mesmo sem o seu suporte direto.

Afinal, a simples exigência de motivação, ainda quando levados em conta todos os argumentos expostos pelas partes litigantes, não é capaz de garantir a legitimidade que se espera de uma decisão em matéria de jurisdição constitucional, com alcance erga omnes e com potencial para se concretizar em precedente obrigatório. O mesmo se pode argumentar - talvez até de modo mais enfático - no que tange ao controle abstrato de constitucionalidade e, atualmente, mesmo diante da objetivação do controle difuso realizado por estas bandas.

Se o processo legislativo demanda uma ampla participação popular, que em moldes de democracia deliberativa não se contenta com a simples representação outorgada pelo voto, o que

60 Ibid. p. 303.

${ }^{61}$ HABERMAS, J. A inclusão do Outro: estudos de teoría política. São Paulo: Edições Loyola, 2002. p. 354.

62 HABERMAS, Jünger. Direito e Democracia: entre facticidade e validade, vol. 1. Tempo Brasileiro: 2000. p. 277.

62 Ibid. p. 299.

Revista do Direito [ISSN 1982-9957]. Santa Cruz do Sul, v. 1, n. 54, p. 99-119, jan./abr. 2018. https://online.unisc.br/seer/index.php/direito/index 
dizer do processo jurisdicional com as características já referidas, em que sequer a representação indireta se encontra presente?

A relevância do papel das cortes constitucionais - em especial, da corte constitucional brasileira - não se coaduna com a ideia de um egocentrismo colegiado, materializado nos discursos tecnicistas restritos aos especialistas, longe de qualquer controle ou participação popular, como ocorre (o controle) com as atividades administrativa e legislativa.

Os anseios de uma sociedade pluralista não se circunscrevem à fase de criação legislativa, mas se prolongam e perduram também para os momentos posteriores, ao longo de sua vigência e, de modo especial, no momento de sua aplicação. Quando este momento se encontra em um processo de caráter abstrato e prospectivo, não parece haver razão que permita prescindir dos diversos pontos de vista aprioristicamente legítimos.

Adequada, por isso, a ideia de Peter Häberle acerca de uma Constituição que não se contenta com a interpretação restrita àqueles que habitam o espaço físico do tribunal constitucional, mas que se abre a toda a sociedade, dado forma à já comentada "sociedade aberta dos intérpretes da constituição". Como bem argumenta Häberle:

Uma Constituição que estrutura não apenas o Estado em sentido estrito, mas também a própria esfera pública, dispondo sobre organização da própria sociedade e, diretamente, sobre setores da vida privada, não pode tratar as forças sociais e privadas como meros objetos. Ela deve integrá-las ativamente enquanto sujeitos. [...] Limitar a hermenêutica constitucional aos intérpretes 'corporativos' ou autorizados jurídica ou funcionalmente pelo Estado significaria um empobrecimento ou um autoengodo. De resto, um entendimento experimental da ciência do Direito Constitucional como ciência de normas e da realidade não pode renunciar à fantasia e à força dos intérpretes "não corporativos". ${ }^{63}$

E, assim como Habermas, o Autor situa a questão da legitimação sobre a força democrática, que se desenvolve por meio de "formas refinadas de mediação do processo público e pluralista da política e da práxis cotidiana, especialmente mediante a realização dos direitos fundamentais" ${ }^{\prime 64}$. Para Häberle:

Povo não é apenas um referencial quantitativo que se manifesta no dia da eleição e que, enquanto tal, confere legitimidade democrática ao processo de decisão. Povo é também um elemento pluralista para a interpretação que se faz presente de forma legitimadora no processo constitucional: como partido político, como opinião científica, como grupo de interesse, como cidadão.

Este último, o cidadão, é o verdadeiro intérprete da constituição em uma democracia deliberativa, concebida sob e sobre a ideia dos direitos fundamentais, seja no que tange ao direito de participação - e de não participação - seja no que tange a todo e qualquer direito dotado de igual fundamentalidade.

Somente um tal tipo de entendimento é capaz de situar o cidadão como destinatário e autor do direito que o regula, garantindo a legitimação das interpretações levadas a efeito em sede de jurisdição constitucional, em especial aquelas que concernem ao alcance dos direitos fundamentais.

63 HÄBERLE, P. Hermenêutica Constitucional: a sociedade aberta dos intérpretes da Constituição. Porto Alegre: Sergio Antonio Fabris Editor, 1997. p. 33-34.

${ }^{64}$ Ibid. p. 36.

Revista do Direito [ISSN 1982-9957]. Santa Cruz do Sul, v. 1, n. 54, p. 99-119, jan./abr. 2018. https://online.unisc.br/seer/index.php/direito/index 
Para conferir uma breve concretude ao que aqui se diz, basta que se rememore o julgamento conjunto da Ação Direta de Inconstitucionalidade no 4277 e da Arguição de Descumprimento de Preceito Fundamental № 132, no Supremo Tribunal Federal, acerca da controvérsia envolvendo 0 art. 226 da Constituição Federal e o reconhecimento da união estável entre pessoas do mesmo sexo. 0 exemplo é paradigmático na medida em que condensa os argumentos que foram até aqui lançados.

Cuida-se, por um lado, de um exemplo nítido de decisão judicial que inova a ordem jurídica, na medida em que reconhece, mesmo sob a aparente contradição ao texto constitucional, como entidade familiar, a união estável entre pessoas do mesmo sexo. Não se está aqui, como já dito, a questionar a legitimidade de tal decisão à luz da separação de poderes, mas a constatar uma realidade que reclama uma maior atenção à atividade da jurisdição constitucional.

Por outro lado, trata-se de decisão construída a partir de ampla participação de setores organizados da sociedade civil, que sob a roupagem dos amici curiae tiveram amplíssima participação no processo de entendimento que culminou na concretização da norma final.

Esse tipo de abertura da Corte Constitucional à práxis argumentativa atenua a tensão entre a facticidade e a validade da norma constitucional, objeto de tanta atenção na obra de Habermas. Em outras palavras, a participação democrática em um processo discursivo permite a interligação entre a realidade constitucional e sua interpretação, conferindo, no mínimo, um nível muito mais seguro de legitimidade - se é que se faz possível esta graduação - à decisão tomada.

Parece adequada, assim, a ideia de Marcos César Botelho acerca da Corte Constitucional como espaço público por excelência na concretização do agir comunicativo, nos moldes propostos por Habermas, "aberto à participação de todos os interessados, em prol de uma busca cooperativa da verdade, no caso, representada por uma hermenêutica do texto constitucional que seja efetivamente resultado de uma práxis argumentativa democrática ${ }^{65}$.

O processo judicial, assim, na jurisdição constitucional, deve ser visto ele próprio como um direito fundamental, ao mesmo tempo que se apresenta como um catalisador dos direitos de participação e da soberania popular, instrumentalizado de institutos que garantam a ampla participação da sociedade.

Os cidadãos, em especial por meio de entidades organizadas da sociedade civil, devem ser admitidos no círculo de uma comunidade de fala comprometida com o entendimento em busca de um consenso - sempre contingente, por óbvio.

Devem, nesse círculo, ser convidados, sem coações ou pressões, a expor seus argumentos, estando dispostos à defesa de suas pretensões de validade, sempre que se fizer necessário, permitindo que o resultado final seja determinado precipuamente pelo som das melhores razões, tendo em conta a aplicação do princípio do discurso, sem se descuidar dos limites estabelecidos pelo direito.

\section{CONCLUSÃO}

65 BOTELHO, M. C. A Legitimidade da Jurisdição Constitucional no Pensamento de Jürgen Habermas. São Paulo: Editora Saraiva, 2010. 
Embora Habermas não transporte de forma evidente sua ideia de democracia procedimental para o âmbito da jurisdição constitucional, parece construir bases mais que suficientes para essa operação.

A tessitura aberta do texto constitucional não permite que se ignore a jurisdição constitucional como instância complementar na produção da norma, mediante um complexo processo de interpretação, que termina por colmatar o trabalho iniciado pelo legislador democrático.

Também os frequentes questionamentos acerca da legitimidade democrática das decisões abstratas tomadas pela Corte Constitucional, põe em evidência a defasagem representativa do Poder Judiciário frente à função legislativa e administrativa do Estado, o qual carece de mecanismos diretos de controle pelos cidadãos.

Tais fatores fazem da jurisdição constitucional um campo fértil para se pensar num horizonte de participação direta do cidadão, por meio de um procedimento no qual a sociedade destinatária dos comandos mais amplos da jurisdição possam, também, participar como seus coautores, diretamente ou por meio de setores organizados da sociedade civil, em uma arena aberta para a exposição de argumentos, sem coação, com o compromisso de justificar as pretensões de validade garantidoras do agir comunicativo, sempre que necessário.

Embora se deva sempre ter em vista os limites inerentes à atividade jurisdicional - em especial no que a diferencia da atividade legislativa - , bem como à necessidade de limites normativamente bem definidos para se garantir a própria efetividade e racionalidade do processo, a ideia de uma sociedade aberta da constituição participante de um agir comunicativo voltado ao entendimento afigura-se, no mínimo, adequada no contexto de uma jurisdição constitucional criativa que tem questionada a legitimidade de suas decisões.

Apenas o exercício de uma jurisdição constitucional voltada para as bases da soberania popular e dos direitos fundamentais - especialmente o direito de participação - é capaz de harmonizar os dissensos existentes em uma sociedade plural e demonstrar a legitimidade de suas decisões a partir de um agir comunicativo racional enfeixado pelos próprios destinatários da norma final constante do comando decisório.

O processo desenvolvido em sede de jurisdição constitucional, assim, mostra-se como espaço público propício à participação comunicativa dos interessados em um procedimento catalizador dos anseios morais e democráticos de uma sociedade complexa, à luz do código do direito, construído pelo entendimento, em busca de uma decisão que, se não é capaz de gerar um consenso, é, no mínimo, a que melhor equaliza os dissensos, na medida em que os resultados estarão sempre pautados pela aplicação procedimental do princípio do discurso.

\section{REFERÊNCIAS}

AUSTIN, John Langshaw. Quando Dizer é Fazer: palavras e ação. Tradução Danilo Marcondes de Souza Filho. Porto Alegre: Artes Médicas, 1990. 
BOTELHO, Marcos César. A Legitimidade da Jurisdição Constitucional no Pensamento de Jürgen Habermas. São Paulo: Editora Saraiva, 2010.

CASTIM, Fernando. John Austin e os atos de fala. In Revista Ágora Filosófica da Universidade Católica de Pernambuco. Ano 17. n 1. jan-jun 2017. Disponível em www.unicap.br/ojs/index.php/agora/article/download/1004/865. Acesso em 15 nov. 2017.

HÄBERLE, Peter. Hermenêutica Constitucional: a sociedade aberta dos intérpretes da Constituição: contribuição para a interpretação pluralista e 'procedimental' da Constituição". Tradução: Gilmar Ferreira Mendes. Porto Alegre: Sergio Antonio Fabris Editor, 1997.

HABERMAS, Jünger. A inclusão do Outro: estudos de teoría política. Tradução: George Speber. São Paulo: Edições Loyola, 2002.

HABERMAS, Jürgen. Direito e democracia: entre facticidade e validade. Vol. I. Tradução: Fabio Beno Siebenneicheler. Tempo Brasileiro: Rio de Janeiro, 2000.

HABERMAS, Jürgen. Direito e democracia: entre facticidade e validade. Vol. II. Tradução: Fabio Beno Siebenneicheler. Tempo Brasileiro: Rio de Janeiro, 2000.

HABERMAS, Jürgen. Pensamento Pós-Metafísico. Tradução: Fabio Beno Siebenneicheler. Tempo Brasileiro: Rio de Janeiro, 1990.

HABERMAS, Jünger. Racionalidade e Comunicação. Tradução: Paulo Rodrigues. Lisboa: Edições 70, 2002.

HABERMAS, Jünger. Teoria do Agir Comunicativo. Vol. I. Tradução: Fabio Beno Siebenneicheler. São Paulo: Editora Martins Fontes, 2012.

HABERMAS, Jürgen. Teoria do Agir Comunicativo. Vol. 2. Tradução: Fabio Beno Siebenneicheler. São Paulo: Editora Martins Fontes, 2012.

HABERMAS, Jünger. Verdade e justificação: ensaios filosóficos. São Paulo: Loyola, 2004.

PINTO, José Marcelino de Rezende. A teoria da ação comunicativa de Jürgen Habermas: conceitos básicos e possibilidades de aplicação à administração escolar. Paidéia (Ribeirão

Preto), Ribeirão Preto , n. 8-9, p. 77-96, Aug. 1995. Disponível em <http://www.scielo.br/scielo.php?script=sci_arttext\&pid=S0103-863X1995000100007

\&lng=en\&nrm=iso $>$. Acesso em 21 Nov. 2017.

MIRANDA, Maressa da Silva, 0 mundo da vida e o Direito na obra de Jürgen Habermas. Prisma Jurídico 2009, 8. Disponível em:<http://www.redalyc.org/articulo.oa?id=93412810006> ISSN 16774760>. Acesso em 16 nov. 2017.

\section{COMO CITAR ESSE DOCUMENTO:}

DA SILVA, Willy Potrich; FREIRE JR., Américo Bedê. Agir comunicativo e democracia: uma proposta para a legitimação da jurisdição constitucional. Revista do Direito, Santa Cruz do Sul, v. 1, n. 54, p. 99-119, jun. 2018. ISSN 1982-9957. Disponível em: $<$ https://online.unisc.br/seer/index.php/direito/article/view/11398>. Acesso em: doi:http://dx.doi.org/10.17058/rdunisc.v1i54.11398. 